\title{
MULTIVALENT FUNCTIONS WITH VARYING ARGUMENTS
}

\author{
R. M. El-Ashwah, M. K. Aouf, A. A. M. Hassan and A. H. Hassan
}

Abstract. Silverman [4] was defined the class of univalent functions $f(z)=z+\sum_{k=2}^{\infty} a_{k} z^{k}$ for which $\arg \left(a_{k}\right)$ prescribed in such way that $f(z)$ is univalent if and only if $f(z)$ is starlike. In this paper we introduce the subclass of $p$-valent functions with varying arguments, especially $p$-valent starlike functions and $p$-valent convex functions, moreover we give some interesting properties of functions in these classes, including coefficients estimates, distortion theorems and extreme functions.

Mathematics subject classification (2010): 30C45.

Keywords and phrases: Analytic, varying arguments, extreme points.

\section{REFERENCES}

[1] M. K. Aouf, A generalization of multivalent functions with negative coefficients, J. Korean Math. Soc., 25 (1988), no. 1, 53-66.

[2] S. OWA, On new classes of p-valent function with negative coefficients, Simon Stevin 59 (1985), no. 4, 385-402.

[3] D. A. Patil And N. K. ThakARe, On convex hulls and extreme points of p-valent starlike and convex classes with applicients, Bull. Math. Soc. Sci. Math. R. S. Roumaine (N. S.), 27 (1983), no. 75, $145-160$.

[4] H. Silverman, Univalent functions with varying arguments, Houston J. Math., 17 (1981), 283-287. 